Research Article

\title{
Impact of educational intervention on awareness of pharmacovigilance among medical undergraduates in Karnataka, India: a cross-sectional study
}

\author{
Padmanabha Thiruganahalli Shivaraju*, Manu Gangadhar, Ravi Shankar Manchukonda, \\ Chandrakantha Thippeswamy, Neha Krishnegowda
}

Department of Pharmacology, Adichunchanagiri Institute of Medical Sciences, B.G. Nagar, Nagamangala Taluk, Mandya 571448, Karnataka, India

Received: 28 March 2016 Accepted: 27 April 2016

*Correspondence to:

Dr. Padmanabha T. Shivaraju, Email: padmanabhatsp @ gmail.com

Copyright: (C) the author(s), publisher and licensee Medip Academy. This is an openaccess article distributed under the terms of the Creative Commons Attribution NonCommercial License, which permits unrestricted noncommercial use, distribution, and reproduction in any medium, provided the original work is properly cited.

\begin{abstract}
Background: India being a part of national pharmacovigilance program (NPP), its contribution to UMC (Uppsala monitoring centre) is very little and pharmacovigilance program of India (PvPI) is still in its infancy. Lack of vibrant reporting culture necessitates bringing the awareness and importance of it. Objective of this study was to assess the level of knowledge, awareness, and the method of application of pharmacovigilance (PV) and to evaluate the impact of an educational intervention among second year medical students for improving awareness of pharmacovigilance.

Methods: This was a cross-sectional questionnaire based study conducted among 146 students in a tertiary care teaching hospital in B.G. Nagara, Mandya, Karnataka, India. Purpose of the study was explained to all the participants. Pretest questionnaires were distributed and filled questionnaires were collected following the educational intervention through continued medical education (CME), same questionnaire was given as post-test questionnaire. Both the test results were analysed to know the educational impact.

Results: Out of 146, a total 130 medical students were involved in pre and posttest questionnaire. The overall response rates between pre and post intervention had improved in majority of the medical undergraduates which brings out the effectiveness of intervention for improving the reporting system.

Conclusions: Educational intervention was more effective in improving student's knowledge, awareness and applications of pharmacovigilance. Early sensitization through educational interventions in II phase of MBBS itself enhances the reporting frequency in future through their active participation \& emphasizing the need to design the suitable strategies to develop vibrant as well as voluntary reporting culture.
\end{abstract}

Keywords: Pharmacovigilance, Educational intervention, Impact, Awareness

\section{INTRODUCTION}

WHO defines Pharmacovigilance as "the science and activities relating to the detection, assessment, understanding and prevention of adverse effects or any other drug-related problem". ${ }^{1}$

The world health organization (WHO) defines an ADR as "a response to a drug which is harmful and unintended, and which occurs at doses normally used in man for the prophylaxis, diagnosis, or therapy of disease or for the modification of body functions". 2

Adverse drug reactions (ADRs) are one of the leading causes of morbidity and mortality. Previous studies have revealed that around $2.9-5.6 \%$ of all hospital admissions are due to ADRs and as many as $35 \%$ of hospitalized individuals experience an ADR during their period of hospitalization. ${ }^{3}$ 
It is as well a financial burden on health care system due to prolonging the hospital stay and augments the expenditure of the cure. ${ }^{4}$

The pharmacovigilance programme in India (PvPI) started in the year 2010 with a mission to safeguard the health of the Indian population by ensuring that the benefit of using medicine outweighs the risks associated with its use. In spite of the best efforts, still the reporting of serious ADRs rarely exceeds $10 \%$. $^{5,6}$

Although, India is one of participating in national pharmacovigilance program, but its contribution to UMC database is very little. Now a days, participation is increased but not up to mark, due to the absence of a vibrant ADR monitoring system and also lack of a reporting culture among health care professional in India. $^{6}$

In spite of the limitations spontaneous reporting is the backbone of pharmacovigilance and provides valuable information regarding safety of a drug.

The backbone of pharmacovigilance programme lies in active and voluntary participation in spontaneous adverse drug reaction reporting. The existence of under reporting system necessitates the bringing of awareness among the young generation.

Therefore, the study was planned to evaluate the awareness towards pharmacovigilance and ADRs reporting system through educational intervention because undergraduate students are the future doctors where they can observe and cultivate the reporting behaviour so that they can contribute to the patient safety across the world.

The objective of this study was to assess the awareness, method of applications related to pharmacovigilance among MBBS students before and after educational interventions and to know the impact of educational intervention in enhancing pharmacovigilance knowledge.

\section{METHODS}

This study was conducted at Adichunchanagiri institute of medical sciences (AIMS) B.G. Nagara, Mandya, Karnataka, India

\section{Study design}

The study was a cross-sectional, questionnaire based study.

\section{Study population}

146 second year medical undergraduates were involved in the study. Participants involved were in III $^{\text {rd }}$ term.

Ethical clearance was taken from the Institutional Ethics Committee (IEC) of AIMS, B.G. Nagara, Karnataka, India

\section{Data collection}

A closed ended validated questionnaire containing 15 questions with two to four options was given to all the participants. The questionnaire consisted of information about knowledge, attitude and application aspects of ADR reporting system. All underwent an educational intervention on pharmacovigilance, continued medical education by department of pharmacology during December 2015. The participants were given the same questionnaire as post-test. The impact of effectiveness of it among students was evaluated by analysing the results obtained from pre and post-test.

\section{Statistical analysis}

Fully completed data were analysed expressed in percentages (\%) using Microsoft Excel software.

\section{RESULTS}

Out of 146 students $3^{\text {rd }}$ term students, 130 students voluntarily participated and gave completed answers to the pre and post intervention questionnaire. Response rate was $89.04 \%$.

Table 1: Awareness.

\begin{tabular}{|lccc|}
\hline Awareness $(\mathbf{n = 1 3 0 )}$ & $\begin{array}{c}\text { Correct pre educational } \\
\text { intervention response }(\boldsymbol{\%})\end{array}$ & $\begin{array}{c}\text { Correct post educational } \\
\text { intervention response (\%) }\end{array}$ & $\begin{array}{c}\text { \% of response improved } \\
\text { by intervention. }\end{array}$ \\
\hline Definition & 64.62 & 80 & 15.38 \\
\hline Mandatory & 93.08 & 93.85 & 0.77 \\
\hline Most common ADR & 54.62 & 72.31 & 17.69 \\
\hline Related products for reporting & 54.62 & 59.23 & 4.61 \\
\hline Disaster which led to modern PV & 24.64 & 63.85 & 39.21 \\
\hline
\end{tabular}


Table 2: Knowledge.

\begin{tabular}{|lccc|}
\hline $\begin{array}{l}\text { Knowledge } \\
(\mathbf{n = 1 3 0 )}\end{array}$ & $\begin{array}{c}\text { Correct pre educational } \\
\text { intervention response (\%) }\end{array}$ & $\begin{array}{c}\text { Correct post educational } \\
\text { intervention response (\%) }\end{array}$ & $\begin{array}{l}\text { \% of response improved } \\
\text { by intervention. }\end{array}$ \\
\hline Reporting centers & 21.54 & 39.23 & 17.69 \\
\hline Inauguration year & 29.23 & 41.54 & 12.31 \\
\hline Responsibility in clinical trial & 58.46 & 75.38 & 16.92 \\
\hline National pharmacovigilance program centre & 32.31 & 51.54 & 19.23 \\
\hline CDSCO South sub zonal located at & 51.54 & 57.69 & 6.15 \\
\hline Uppsala located at & 27.69 & 85.38 & 57.69 \\
\hline
\end{tabular}

Table 3: Method of applications.

\begin{tabular}{|lccc|}
\hline $\begin{array}{l}\text { Method of applications } \\
\text { (n=130) }\end{array}$ & $\begin{array}{c}\text { Correct pre educational } \\
\text { intervention response }\end{array}$ & $\begin{array}{c}\text { Correct post educational } \\
\text { intervention response (\%) }\end{array}$ & $\begin{array}{c}\text { \% of response improved } \\
\text { by intervention. }\end{array}$ \\
\hline Who can report & 61.54 & 76.92 & 15.38 \\
\hline Reporting centre sequence & 36.92 & 43.08 & 6.16 \\
\hline Causality assessment & 30.77 & 50 & 19.23 \\
\hline Red card system & 20.77 & 53.85 & 33.08 \\
\hline Mandatory elements & 61.54 & 78.46 & 16.92 \\
\hline Dechallenge & 31.54 & 43.08 & 11.54 \\
\hline Reporting common ADR & 73.85 & 76.92 & 3.07 \\
\hline Online reporting system & 30 & 57.69 & 27.69 \\
\hline ADR synonymous to adverse event (AE) & 47.70 & 73.85 & 26.15 \\
\hline
\end{tabular}

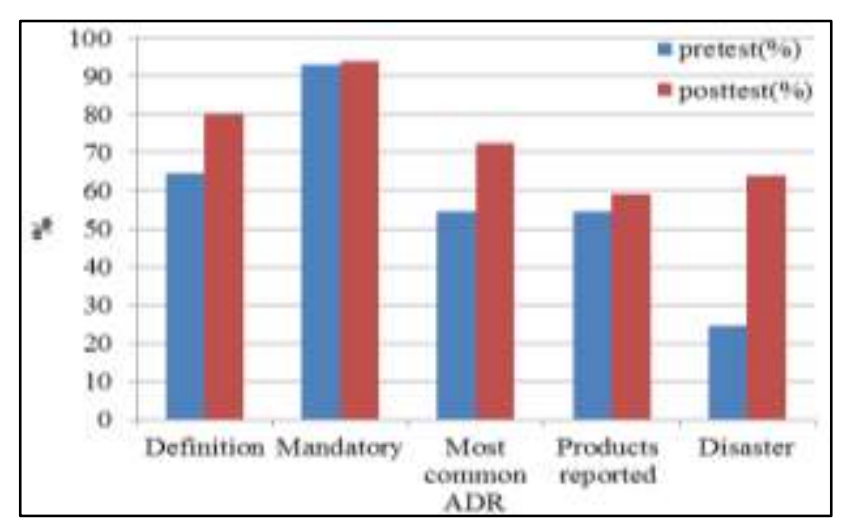

Figure 1: Awareness.

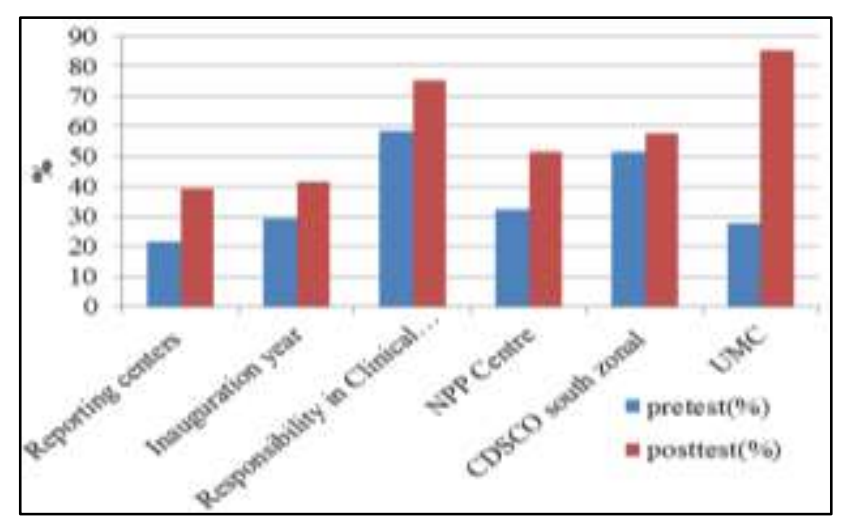

Figure 2: Knowledge.

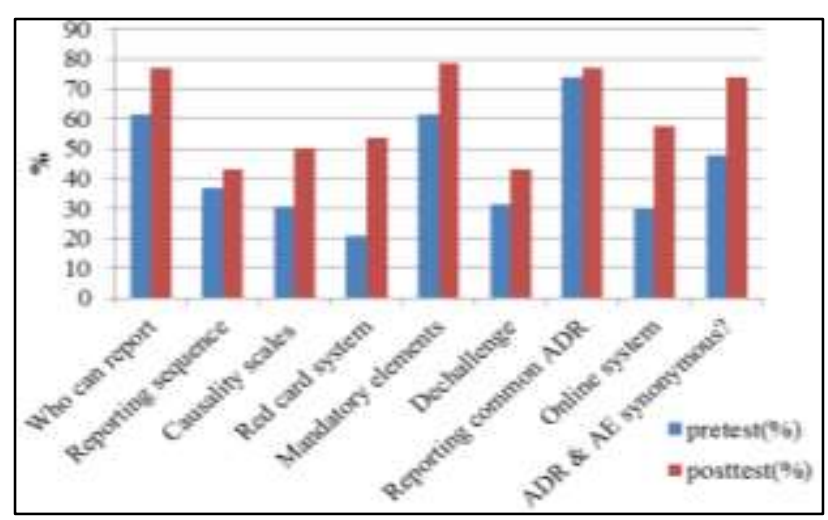

Figure 3: Methods of applications.

There was an overall improvement in all the three aspects i.e. Awareness, knowledge and its applications.

Results were significant with respect to, Uppsala monitoring centre (57.69\% improvement) disaster which led to modern PV (39.21\% improvement), red card system (33.08\% improvement), system for online reporting (27.69\% improvement), difference between ADR and adverse event (26.15\% improvement). Apart from this they also showed improvement towards definition (15.38\%), most common ADR (17.69\%), trial responsibilities (16.92), NPP centre (19.23\%). Reporting nature i.e. regarding the personals who can report $(15.38 \%)$, scales for assessment (19.23\%) and mandatory elements to be filled (16.92\%). 


\section{DISCUSSION}

MCI (medical council of India) recommends including pharmacovigilance and ADR reporting curriculum to second year medical undergraduate, so that they acquire basic structural and functional concepts. ${ }^{7}$

Our study result shows that, overall knowledge after the educational intervention was fairly good and improved a lot when compared to pre interventional results. Our undergraduates were aware of national and international pharmacovigilance centre for reporting ADRs, its causality assessment, reporting system involved from peripheral monitoring centre until it reaches the Uppsala monitoring centre. Professionals involved and the adverse reaction from various products that needs to be reported in creating a very active and vibrant voluntary reporting culture through continuous everlasting encouragement to the all health care professionals, so that we can have our nations own data base for the safety of mankind and for their welfare.

Pharmacovigilance programme plays a very vital role in detection of ADRs and banning of several drugs which otherwise may prove fatal consequences in future. ${ }^{8}$

The present study results were in par with the study done by Joseph et al in which there was improvement in terms of knowledge and awareness of pharmacovigilance among medical undergraduate students. ${ }^{9}$

Our study goes hand in hand with the results of the study done by Sanghavi et al, Hardeep et al, Manuela Tabali et al in which intervention improved knowledge of the participants about ADR reporting system. ${ }^{10-12}$ All these study demonstrated that an educational intervention could increase the awareness on ADRs among practitioners and they could incorporate the knowledge gained from training into their everyday clinical practice for the success of PvPI.

Response of students in our study group regarding ADR monitoring showed that educational intervention has improved their knowledge towards practice of reporting ADRs.

The limitations of this study was small sample size and study results cannot be generalized as it was conducted in single centre; hence there is a need to conduct more multicentric studies among undergraduate medical students including all the allied health care personals.

\section{CONCLUSION}

Our study strongly suggests that there is a urgency of creating awareness among the medical students to improve the reporting culture of ADRs. Time to time continued medical education (CME) programs, symposium regarding spontaneous reporting of adverse drug reactions and training sessions, must clarify the roles various healthcare professionals including medical undergraguate, a future budding doctors in pharmacovigilance. Pharmacovigilance programme of India (PvPI) should be made an integral part of medical education in order to improve ADR monitoring and patient care. Thus, it forms a basis for solid foundation about pharmacovigilance programme among students.

\section{ACKNOWLEDGEMENTS}

We express our thankfulness to undergraduates, teaching faculty in our institution, institutional ethics committee for facilitating the smooth conduct of the study.

\section{Funding: No funding sources}

Conflict of interest: None declared

Ethical approval: The study was approved by the Institutional Ethics Committee

\section{REFERENCES}

1. WHO pharmacovigilance. Available at www.who.int/medicines /areas/quality_safety/safety_ efficacy/pharmvigi/en/. Assessed 27 January 2016.

2. World Health Organization. Requirements for adverse reaction reporting. Geneva, Switzerland: World Health Organization; 1975.

3. Baniasadi SH, Fahimi F, Shalviri G. Developing an adverse drug reaction reporting system at a teaching hospital. Basic Clin Pharmacol Toxicol. 2008;102:408-11.

4. Sultana J, Cutroneo P, Trifirò G. Clinical and economic burden of adverse drug reactions. J Pharmacol Pharmacother. 2013;4(1):73-7.

5. Green CF, Mottram DR, Rowe PH, Pirmohamed M. Attitudes and knowledge of hospital pharmacists to adverse drug reaction reporting. Br J Clin Pharmacol. 2001;51:81-6.

6. Feely J, Moriarty S, O'Connor P. Stimulating reporting of adverse drug reactions by using a fee. BMJ. 1990;300:22-3.

7. Prerna U, Vikas S, Vijay VM, Monika S, Mushtaq A. Knowledge of adverse drug reaction reporting in first year postgraduate doctors in a medical college. Ther Clin Risk Manag. 2012;8(1):307-12.

8. Irujo M, Beitia G, Bes-Rastrollo M, Figueiras A, Hernández DS, Lasheras B. Factors that influence under-reporting of suspected adverse drug reactions among community pharmacists in a Spanish region. Drug Saf. 2007;30(11):1073-82.

9. Joseph LR, Palappallil DS. Impact of a simple educational intervention on the knowledge and awareness of pharmacovigilance among medical undergraduate students. Int $\mathrm{J}$ Med Phar Sci. 2015;6(3):5-9.

10. Sanghavi DR, Dhande PP, Pandit VA. Perception of pharmacovigilance among doctors in a tertiary care hospital: influence of an interventional lecture. Int J Risk Saf Med. 2013;25:197-204. 
11. Hardeep, Bajaj JK, Kumar R. A survey on the knowledge, attitude and the practice of pharmacovigilance among the health care professionals in a teaching hospital in Northern India. J Clin Diagn Res. 2013;7:97-9.
12. Tabali M, Jeschke E, Bockelbrink A, Witt CM, Willich SN, Ostermann T, et al. An educational intervention to improve the physician reporting of the adverse drug reactions (ADRs) in a primary care setting in the complementary and alternative medicine programs. BMC Public Health. 2009;9:274.

Cite this article as: Shivaraju PT, Gangadhar M, Manchukonda R, Thippeswamy C, Krishnegowda $\mathrm{N}$. Impact of educational intervention on awareness of pharmacovigilance among medical undergraduates in Karnataka, India: a crosssectional study. Int J Basic Clin Pharmacol 2016;5:986-90. 